\title{
Commentary: The path to prophylaxis for predictable palpitations
}

\author{
Jonathan D. Spicer, MD, PhD, FRCSC
}

\footnotetext{
From the Division of Thoracic and Upper Gastrointestinal Surgery, McGill University, Montreal General Hospital, Montreal, Quebec, Canada.

Disclosures: Author has nothing to disclose with regard to commercial support.

Received for publication Feb 4, 2019; accepted for publication Feb 5, 2019; available ahead of print March 21, 2019.

Address for reprints: Jonathan D. Spicer, MD, PhD, FRCSC, Division of Thoracic and Upper Gastrointestinal Surgery, McGill University Montreal General Hospital, L8.520 1650 Cedar Ave, Montreal, Quebec Canada H3G 1A4 (E-mail: jonathan.spicer@mcgill.ca).

J Thorac Cardiovasc Surg 2019;157:2500-1

$0022-5223 / \$ 36.00$

Crown Copyright $@ 2019$ Published by Elsevier Inc. on behalf of The American Association for Thoracic Surgery https://doi.org/10.1016/j.jtcvs.2019.02.021
}

The American Association for Thoracic Surgery guidelines for postoperative atrial fibrillation (POAF) prevention after general thoracic operations highlight the importance of a perioperative strategy to minimize the occurrence and impact of POAF. ${ }^{1}$ Many of the proposed interventions have some undesirable toxicities or are of little use if applied to a low-risk population. In this issue of the Journal, Amar and colleagues ${ }^{2}$ demonstrate many well-known predictors of POAF and highlight the added value of preoperative B-type natriuretic peptide levels to more accurately predict this common complication. This study is both convincing and important as it provides a simple prediction tool via an online calculator. The added length of stay and cost of care in patients with isolated POAF after thoracic surgery are well documented. ${ }^{3}$ Indeed, thoracic surgery units around the world could benefit from implementing this simple tool to their preoperative planning for major pulmonary or esophageal surgery. The approach derives accurate prediction metrics from a simple biometric panel including 5 variables: age, body mass index, B-type natriuretic peptide, history of atrial fibrillation, and extent of surgery.

However, POAF is frequently associated with a multitude of other postoperative complications, such as pneumonia or anastomotic leak. It is unclear whether the proposed nomogram will help differentiate between cases in which POAF occurs as the result of a pharmacologically modifiable preexisting cardiac susceptibility versus cases in which management of an underlying infectious/ inflammatory complication is the key to achieving resolution of POAF. The core question of how POAF prevention can mitigate the occurrence of secondary morbidity, such as devastating thromboembolic events, remains open.

Furthermore, the ardor with which thoracic surgery units pursue the diagnosis of POAF after routine thoracic

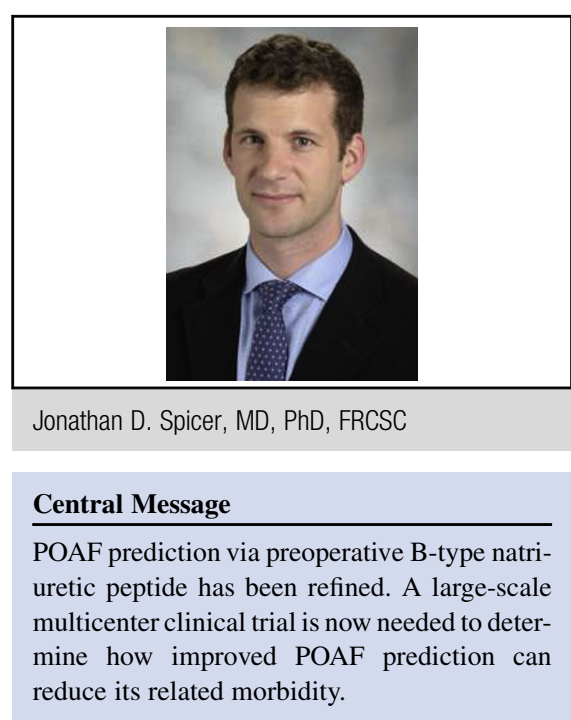

See Article page 2493. surgery varies tremendously. Unfortunately, not all thoracic surgery units around the world share the same abundant resources as those that were available to the patients who contributed to this study by Amar and colleagues. $^{2}$ Continuous cardiac monitoring for 48 to 72 hours after routine operations, such as anatomic lung and esophageal operations, although potentially preferable is not universally feasible. In fact, enhanced recovery pathways and minimal access surgery programs routinely lead to patient discharge within 24 to 48 hours from surgery. This new reality significantly limits our ability to detect POAF by conventional means. Do such patients go on to experience severe POAF-related complications? If so, how do we capture these events in the outpatient setting, and more important, how do we prevent them? Or is the event rate so low that the means do not justify the ends?

Although the authors have made a great advance in terms of refining our predictive abilities to identify at-risk populations, we remain limited in our understanding of how this new insight could offer significant gains to our patients. What is clear to me is that Amar and colleagues ${ }^{2}$ have provided us with a foundational approach to the problem of POAF prediction, and this is a key element to the multicenter prospective trial required to establish a modern understanding of POAF prevention strategies and their wider 
impact on patients undergoing major general thoracic operations.

\section{References}

1. Frendl G, Sodickson AC, Chung MK, Waldo AL, Gersh BJ, Tisdale JE, et al. 2014 AATS guidelines for the prevention and management of perioperative atrial fibril- lation and flutter for thoracic surgical procedures. J Thorac Cardiovasc Surg. 2014;148:e153-93.

2. Amar D, Zhang H, Tan KS, Piening D, Rusch VW, Jones DR, et al. A brain natriuretic peptide-based prediction model for atrial fibrillation after thoracic surgery: development and internal validation. J Thorac Cardiovasc Surg. 2019;157:2493-9.e1.

3. Vaporciyan AA, Correa AM, Rice DC, Roth JA, Smythe WR, Swisher SG, et al. Risk factors associated with atrial fibrillation after noncardiac thoracic surgery: analysis of 2588 patients. J Thorac Cardiovasc Surg. 2004;127:779-86. 